\title{
Erratum to: Lymphotrophic nanoparticle enhanced MR imaging (LNMRI) for lymph node imaging
}

\author{
A. Saokar, ${ }^{1,2}$ M. Braschi, ${ }^{1,2}$ M. Harisinghani ${ }^{1,2}$ \\ ${ }^{1}$ Center of Molecular Imaging and Research, Massachusetts General Hospital, White 270, 55 Fruit Street, Boston, MA 02114, USA \\ ${ }^{2}$ Department of Radiology, Division of Abdominal Imaging and Intervention, Massachusetts General Hospital, White 270, \\ 55 Fruit Street, Boston, MA 02114, USA
}

\section{Erratum to: Abdom Imaging (2006) 31:660-667 DOI 10.1007/s00261-006-9006-2}

This article was inadvertently published a second time under DOI: 10.1007/s00261-006-9119-7.

Official publication is under DOI: 10.1007/s00261-006-9006-2 in Abdom Imaging (2006) 31:660-667.

The online version of the original article can be found under doi:10.1007/s00261-006-9006-2.

Correspondence to: M. Harisinghani; email: mharisinghani@partners.

org 